\title{
Measurement of pressure walking in footwear used in leprosy
}

\author{
JAMES A. BIRKE*, JAMES G. FOTO†, \\ SUNIL DEEPAK $\ddagger \&$ JEAN WATSON $\S$ \\ *Physical Therapy Department, Gillis W. Long Hansen's Disease \\ Center, Carville, LA 70721, USA; †Rehabilitation Research \\ Department, Gillis W. Long Hansen's Disease Center, Carville, \\ LA, 70721, USA; $¥$ Medical Consultant, AIFO, Via Borselli 4, \\ 40135 Bologna, Italy; and §Consultant Physiotherapist, The \\ Leprosy Mission, London, 50 Portland Place, London WIN 3DG
}

\section{Accepted for publication 4 February 1994}

Summary Pressure measurements were made on 10 leprosy patients while walking barefoot and while using 6 sample shoes. The sample shoes, which represented footwear currently used worldwide in leprosy programmes, included: 1, a USA extradepth shoe without insole; 2, a USA extradepth shoe with insole; 3, a Chinese tennis shoe; 4, a Mozambique sandal; 5, a Bombay sandal; 6, a Bombay sandal with rigid sole; and 7, the patients' prescribed footwear. Peak pressure was significantly lower while walking in all footwear, except with the extradepth shoe without an insole, when compared to barefoot walking. Peak pressure was significantly lower walking in the Bombay sandals, the Chinese tennis shoe, the extradepth shoe with an insert and the patients' prescribed shoe when compared to the extradepth shoe without an insert. Regression analysis showed a significant inverse relationship between pressure and insole thickness $\left(P<0 \cdot 001, R^{2}=0 \cdot 17\right)$.

\section{Introduction}

Neuropathic plantar ulcerations usually result from repetıtıve stress on the foot. ${ }^{1,2}$ Studies demonstrate that neuropathic plantar ulcerations develop over areas of high pressure associated with deformity or joint limitation. ${ }^{3-5}$

Footwear and insoles designed with soft elastic materials, moulded insoles and/or rigid rocker soles have been recommended to reduce pressure and prevent plantar ulceration in leprosy. ${ }^{6-10}$ The effectiveness of these devices has been generally based on qualitative measurements using the Harris mat and Carville microcapsule socks. ${ }^{11,12}$ Bauman et al. ${ }^{13}$ demonstrated, using noncommercial pressure transducers, the effectiveness of soft material and a rigid rocker sole on reducing plantar pressure. Transducer systems, however, provide only limited measurement of plantar pressure and suffer from 
measurement errors due to sensor thickness, movement, and interaction of the foot/shoe interface on the transducer. ${ }^{1114}$ The recent development of commercially available inshoe pressure measurement systems (FSCAN, Tekscan Inc, Boston, MA and EMED, Novel USA, Minneapolis, MN) have provided the methodology to quantitatively evaluate footwear and insole designs. These systems utilize inshoe mats containing an array of sensors which measure pressure over the entire plantar surface of the foot. The FSCAN sensor mat, measuring $0.178 \mathrm{~mm}$ thick, should minimize measurement error resulting from interactions at the foot/sensor/shoe interface.

Rose et $a l .{ }^{15}$ found, using an early version of FSCAN (version 1.20), that the system was reliable when the same sensor was used for repeated tests of less than 12 walking trials. Variation was noted between sensors, and after 12 walking trials pressure measurements significantly decreased. The FSCAN manufacturer has developed new sensors designed to be resistent to failure, and the updated software (version 3.601) provides for sensor calibration before testing.

Patients with sensory loss and deformity are considered to be at high risk of ulceration. ${ }^{16}$ High-risk patients should be provided with protective footwear as part of a foot deformity prevention programme. Demonstrating the effectiveness of protective footwear is a critical issue for prevention programmes. ${ }^{14}$ Programme managers and clinicians need data to support the purchase and distribution of specific footwear designs. Footwear should be shown to be effective in reducing pressure, not harmful to the foot, acceptable to the patient, and cost-effective.

\section{Method}

This study evaluated the effectiveness of a sample of footwear currently used by leprosy sufferers. The footwear tested were selected by The Footwear Committee, The Leprosy Mission. Inshoe pressure measurements were made on 9 male and 1 female leprosy patients of the Gillis W. Long Hansen's Disease Center, Carville, LA. Measurements were made during walking using the FSCAN System (software version 3.601) and concurrently using the EMED Platform (Novel USA, Minneapolis, MN) during barefoot walking. The peak pressure for the patients' high risk area on the barefoot trial was used for comparisons (Figure 1). Measurements were made in the middle of a 20 foot walking trial. Each FSCAN sensor was calibrated before testing using a pneumatic calibration device (Novel USA, Minneapolis, MN). Measurement of a standard $500 \mathrm{KPa}$ pressure was made before and after testing each subject. Speed of walking was measured using a photoelectric trigger (Model 49310, Radio Shack, Fort Worth, TX) and electronic counter (DC 503 Universal Counter, Tectronix, Inc, Beaverton, $O R$ ) to maintain a self-selected pace during each trial. The test conditions (Figure 2) for each subject included:

\section{1 barefoot;}

2 extra depth shoe (P. W. Minor Shoes, USA) with a poron insole;

3 extra depth shoe (P. W. Minor Shoes, USA) without an insole;

4 tennis shoe (commercial, China) with 2 microcellular rubber insoles;

5 sandal (handmade, Mozambique) with a microcellular insole;

6 sandal (commercial, Bombay) with a microcellular rubber insole; 
7 sandal (commercial, Bombay) with a microcellular rubber insole and metal stave for rigidity; and

8 the patients' prescribed footwear (not standardized)

Test conditions were randomized by lottery. The mean of 4 steps of walking were used to analyse pressure during walking. Statistical analysis was made using an analysis of variance for repeated measures. A Duncan's test was used for comparisons between test conditions. A Pearson correlation and a paired $t$-test were used to compare concurrent validity of FSCAN and EMED measurements barefoot. A paired $t$-test was used for comparison of the standard $500 \mathrm{KPa}$ load before and after testing to determine if there was a systematic source of measurement error.

Footwear were compared for the following design characteristics: insole thickness, insole firmness, toespring height, heel height, sole firmness, and sole stiffness (Table 1). A

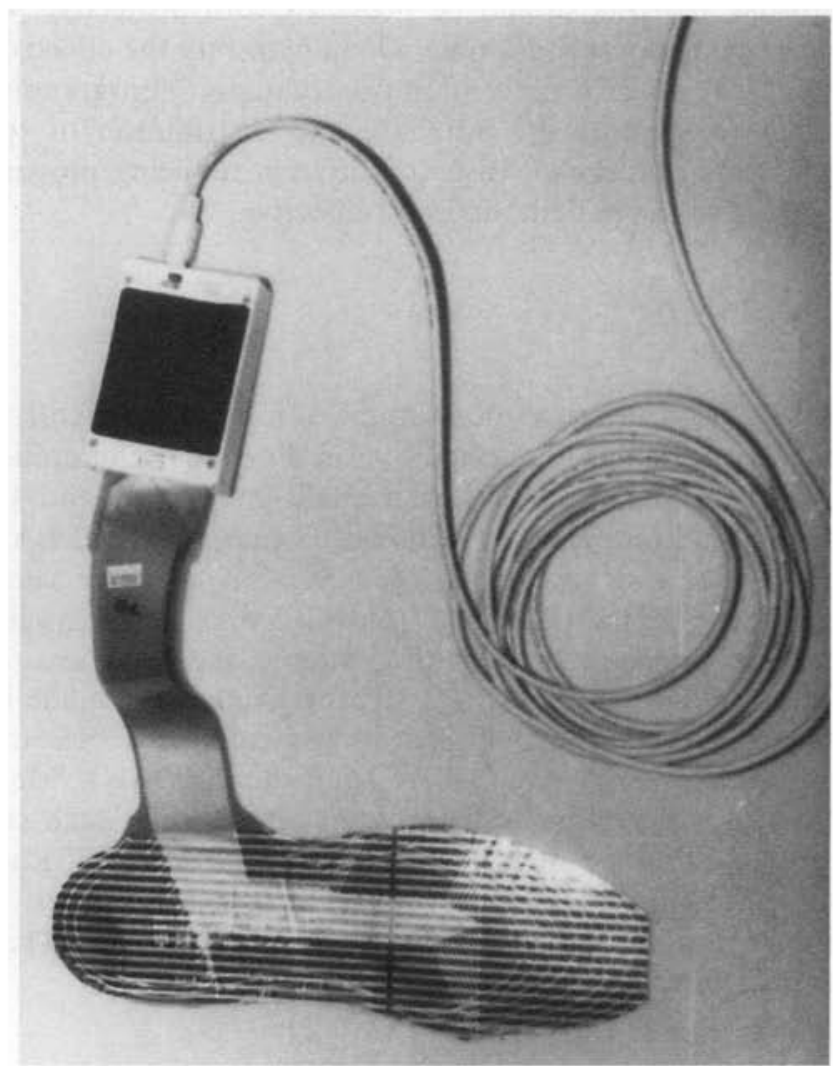

Figure 1(a)

Figure 1. (a) FSCAN inshoe pressure sensor and cuff unit; (b) 3-dimensional FSCAN recording barefoot shows the great toe to be the high risk area in this patient; (c) numerical mapping for the same step baref oot shows the peak pressure to be $1620 \mathrm{KPa}$; (d) 3-dimensional recording on the same individual walking in the Bombay sandal shows a significant reduction in peak pressure at great toe; (e) numerical mapping for the same step in the Bombay sandal shows the peak pressure at the great toe to be $688 \mathrm{KPa}$. 



$\begin{array}{lllll}61 & 49 & 49 & 61 & 49\end{array}$

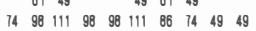

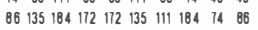

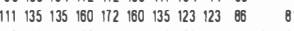

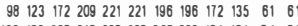

$12317225824625825825823318418474 \quad 81$

$147258258295319319282270246246160 \quad 86$

$233332307368430405332307282282196 \quad 86 \cdot 49$

$246356393467442405356332307282 \quad 172 \quad 74 \quad 74$

$2333934304915284543563344258344 \quad 86 \quad 61 \quad 74$

172368442454442405332319233233

74270356381393356307258233135

$209270258307282319258270 \quad 49$

$86147209221221209246 \quad 111$

$$
11113516022198
$$

Figure 1(b) and (c) 


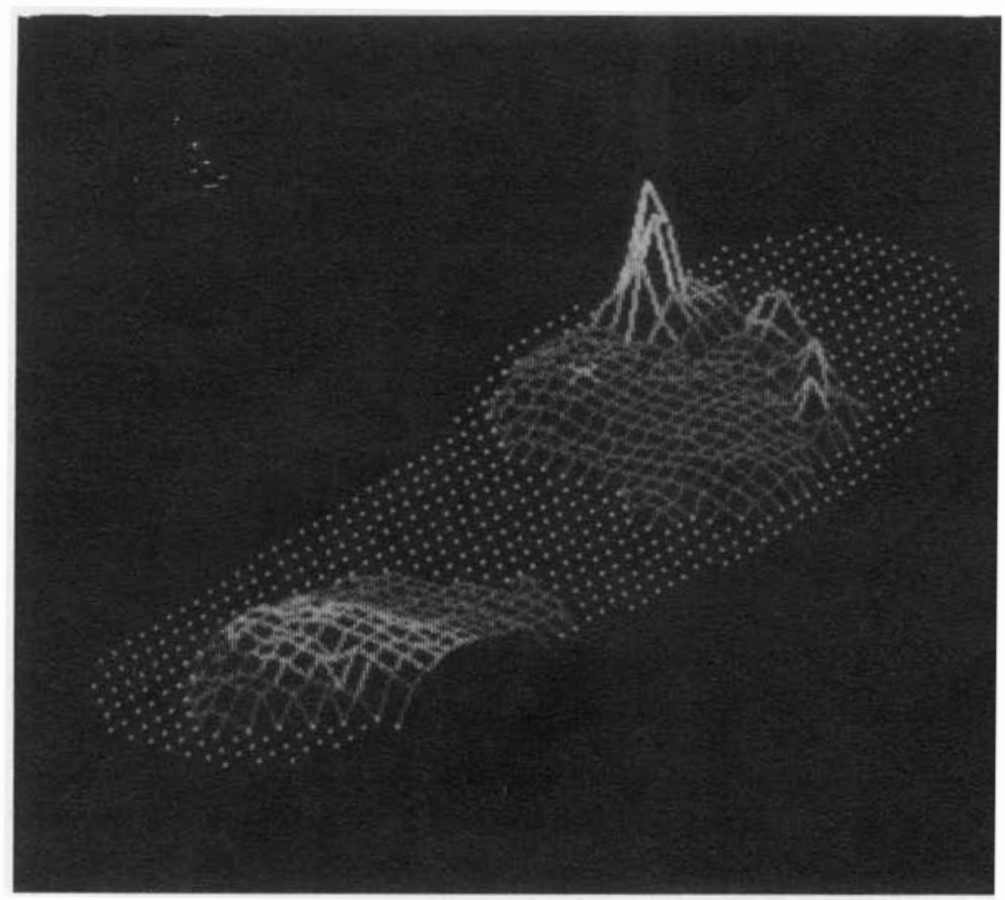



$23319818074 \quad 180 \quad 1841358649$

3448885402091808612313598111221

$209356589270180818811149111111 \quad 88 \quad 49$

$184295418184 \quad 111 \quad 861111111111 \quad 61 \quad 61 \quad 98 \quad 123$

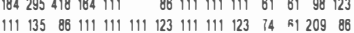

$81135111135 \quad 23 \quad 7412312312311111111198 \quad 61 \quad 86$

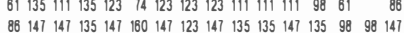



$\begin{array}{llllllllllllllll}86 & 123 & 172 & 135 & 160 & 147 & 135 & 147 & 147 & 123 & 135 & 147 & 147 & 111 & 86 & 74 \\ 74 & 123 & 180 & 172 & 160 & 160 & 147 & 135 & 335 & 135 & 135 & 160 & 147 & 135 & 111 & 98\end{array}$

$111180172184147135123123123135135147 \quad 12311198$

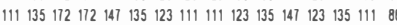

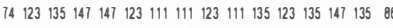

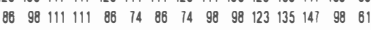

$\begin{array}{lllllllllllllll}81 & 74 & 86 & 81 & 61 & 49 & 61 & 74 & 86 & 111 & 111 & 98 & 88 & 49\end{array}$

$\begin{array}{lllllllllllll}49 & 81 & 81 & 49 & 49 & 49 & 49 & 81 & 74 & 86 & 74 & 49\end{array}$

$\begin{array}{rrr}61 & 61 & 49 \\ 49 & 49\end{array}$

49

$\begin{array}{llllll}49 & 49 & 61 & 49 & 61 \\ 81 & 89\end{array}$

$\begin{array}{llllllllll}49 & 49 & 61 & 61 & 74 & 61 & 74 & 61 & 49\end{array}$

$\begin{array}{llllllllll}49 & 61 & 74 & 74 & 74 & 74 & 74 & 74 & 74 & 61\end{array}$

$\begin{array}{llllllllll}74 & 86 & 86 & 74 & 88 & 86 & 111 & 111 & 98 & 98\end{array}$

$\begin{array}{llllllllllll}74 & 86 & 111 & 86 & 98 & 111 & 111 & 123 & 123 & 98\end{array}$

$\begin{array}{lllllllllllllll}81 & 98 & 111 & 111 & 111 & 123 & 123 & 123 & 147 & 147 & 135\end{array}$

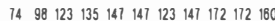

61 $123180172172184198198 \quad 198184184$

11113519810422124023322123304184

123184184221233258248

123104104221233258246233209209190

135196221209233258233233233209172

123198221209209221
86187221221172
$86021198233233209 \quad 98 \quad 86$

$86 \quad 1802219923323320998 \quad 86$

$\begin{array}{llllll}96 & 172 & 172 & 196 & 196 & 147 \\ 61 & 74 & 123 & 147 & 135 & 123\end{array}$

$49 \quad 23 \quad 35123$

$49 \cdot 49$

Figure 1(d) and (e) 




Figure 2. Footwear used for testing: (left to right) the Chinese tennis shoe, the Bombay sandal, the Mozambique sandal, the USA extradepth shoe.

durometer (type O, Rex Gauge Co, Glenview, IL) was used to measure insole and sole firmness in degrees shore. A cantilever straingauge (GWLHDC, Carville, LA) was used to measure sole stiffness in $\mathrm{mm}$ gm torque (Figure 3 ). Regression analysis was used to show the relationship between foot pressure and footwear characteristics.

\section{Results}

Analysis of variance showed a significant difference in peak pressure between various walking conditions $(p<0 \cdot 0001)$. Duncan's multiple range test showed that all footwear conditions, except the extradepth shoe without an insole, had significantly lower peak pressures when compared to barefoot walking (Table 2). The Bombay sandal, the Chinese tennis shoe, the extradepth shoe with an insert and the patients' prescribed shoe had significantly lower peak pressures compared to the extradepth shoe without an

Table 1. Characteristics of sample footwear

\begin{tabular}{|c|c|c|c|c|c|c|}
\hline Footwear tested & $\begin{array}{c}\text { Toespring } \\
\text { height } \\
(\mathrm{mm})\end{array}$ & $\begin{array}{c}\text { Heel } \\
\text { height } \\
(\mathrm{mm})\end{array}$ & $\begin{array}{l}\text { Insole } \\
\text { thickness } \\
(\mathrm{mm})\end{array}$ & $\begin{array}{c}\text { Insole } \\
\text { firmness } \\
\text { (Durometer) }\end{array}$ & $\begin{array}{c}\text { Outsole } \\
\text { firmness } \\
\text { (Durometer) }\end{array}$ & $\begin{array}{c}\text { Sole } \\
\text { stiff ness } \\
(\mathrm{gm} \mathrm{mm})\end{array}$ \\
\hline Bombay sandal & $14^{*}$ & 9 & 10 & 33 & 68 & 780 \\
\hline Bombay sandal with rigid stave & $14^{*}$ & 9 & 10 & 26 & 68 & 2000 \\
\hline Chinese tennis shoe & 10 & 0 & $14(2$ at $7 \mathrm{~mm})$ & 35 & 72 & 940 \\
\hline Mozambique sandal & $19 *$ & 10 & 5 & 22 & 73 & 730 \\
\hline P. W. minor shoe with insole & 11 & 17 & 7 & 21 & 66 & 1630 \\
\hline P. W. minor shoe without insole & 11 & 17 & 0 & 80 & 66 & 1630 \\
\hline
\end{tabular}

* Measurements variable. 


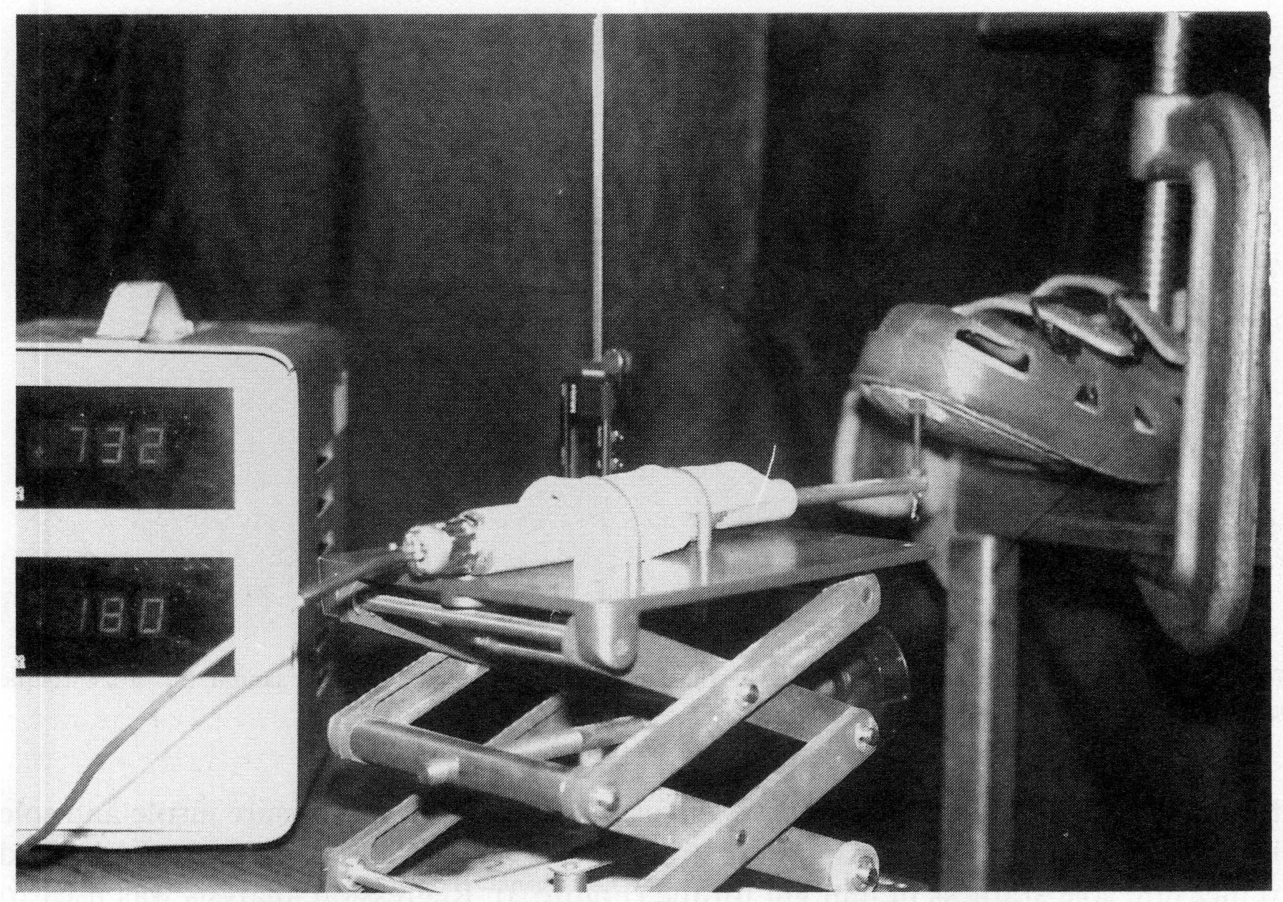

Figure 3. Cantilever straingauge used to measure sole stiffness.

insert. The Chinese tennis shoe and the Bombay sandal without a stave had significantly lower peak pressure than the Mozambique and extradepth shoe without an insole. The patients' prescribed shoe had significantly lower peak pressures than the Mozambique sandal and the extradepth shoe with an insole.

Regression analysis showed a significant inverse relationship between peak pressure and insole thickness ( $\left.p<0 \cdot 001, R^{2}=0 \cdot 17\right)$. A significant relationship was not found for the shoe characteristics of insole firmness, toespring height, heel height, sole firmness, or sole stiffness.

Table 2. Comparison of mean peak walking pressures $(n=10)^{*}$

\begin{tabular}{lcc}
\hline Footwear tested & Mean $(\mathrm{kPa})$ & $\begin{array}{c}\text { Comparison } \\
\text { of means } \dagger\end{array}$ \\
\hline Barefoot & $1194 \cdot 4$ & $\mathrm{a}$ \\
P. W. minor without insole & $985 \cdot 5$ & $\mathrm{a}, \mathrm{b}$ \\
Mozambique & $840 \cdot 7$ & $\mathrm{~b}, \mathrm{c}$ \\
P. W. minor with insole & $645 \cdot 2$ & $\mathrm{c}, \mathrm{d}$ \\
Bombay with stave & $594 \cdot 3$ & $\mathrm{c}, \mathrm{d}, \mathrm{e}$ \\
Chinese & $549 \cdot 2$ & $\mathrm{~d}, \mathrm{e}$ \\
Bombay without stave & $508 \cdot 5$ & $\mathrm{~d}, \mathrm{e}$ \\
Patients prescribed & $359 \cdot 5$ & $\mathrm{e}$ \\
\hline
\end{tabular}

* Peak pressures for patients' high risk area on the barefoot trial. $\uparrow \mathrm{a}>\mathrm{b}>\mathrm{c}>\mathrm{d}>\mathrm{e} ; p<0.05$. 
There was a small but significant difference between the initial and the final $500 \mathrm{KPa}$ standard pressure test $(p<0 \cdot 0265)$. Initial mean pressure was $463.9 \pm 25 \cdot 1 \mathrm{KPa}$ and the final pressure was $430 \cdot 6 \pm 45.9 \mathrm{KPa}$. This represents a $7 \%$ loss in pressure after 7 trials of walking 20 feet.

There was a significant correlation between FSCAN and EMED barefoot measurements $(r=0 \cdot 85, p<0 \cdot 0018)$. Mean FSCAN barefoot measurements $(1199 \cdot 4 \pm 617 \cdot 7 \mathrm{KPa}$, range $295 \cdot 0-2330.0 \mathrm{KPa})$ were significantly higher $(p<0.0607)$ than mean EMED barefoot measurements $(943 \cdot 0 \pm 330 \cdot 5 \mathrm{KPa}$, range $280 \cdot 0-1280 \cdot 0 \mathrm{KPa})$.

\section{Discussion}

These results demonstrate that all the footwear tested were effective in reducing peak walking pressure, apart from the extradepth shoe without an insole. Based on regression analysis, a thick insole was the footwear feature which was most significantly associated with lower pressures. Weak relationships were also found for insole firmness and heel height. Rose et al. ${ }^{15}$ also found heel height was positively related to foot pressure in normal subjects. This study was not designed to show strong relationships between pressure and shoe characteristics, because the footwear tested did not vary greatly for the traits tested. In particular, all the footwear tested had soft insoles except for the extradepth shoe without an insole.

This study investigated whether a stiff versus flexible sole footwear is more effective in reducing pressure. Regression analysis showed no significant relationship between sole stiffness and peak pressure. Peak pressure was not significantly different walking in the Bombay sandal with and without a rigid stave fit beneath the insole. Future studies should be designed to determine the relationship between plantar pressure and shoe characteristics in leprosy patients.

The most effective footwear in this study were the patients' prescribed footwear. The patients' footwear were not standardized, and included cases with moulded insoles and rocker soled shoes. Moulded insoles and rocker sole modifications may more effectively reduce pressure than the flat soft insoles which characterized the footwear sampled in this study. Shoes with flat insoles are easy and inexpensive to produce and ideal for prevention programmes. Further studies are needed to compare the effectiveness of flat soft insoles, moulded insoles, and rocker soles in reducing foot pressure in patients with leprosy.

This study supports the findings of Rose et al. that a reduction in pressure is expected during the continual use of FSCAN sensors. FSCAN sensors should not be used under conditions which require long repeated walking trials, since pressure readings are related to use. Research using the FSCAN should randomly assign treatments so that a systematic error is not caused by the testing order.

The concurrent validity between FSCAN and EMED peak pressure measurements was shown to be good. Peak pressure walking barefoot was higher using the FSCAN when compared to the EMED System, and 2 subjects had readings at the maximum testing range on the barefoot trial for the EMED system. The maximum reading for the EMED system is $1270 \mathrm{KPa}$ and peak pressure was probably underestimated in these cases. Differences in barefoot pressure measured by both systems may have resulted from limitations in the method of calibration of the FSCAN sensors. The EMED system 
provides for calibration of individual transducers within the platform. The FSCAN system provides for the calibration of the entire sensor but not the individual sensels. However, we have not found sensels to vary greatly from each other after calibration. In this study, FSCAN sensors were calibrated cold while walking measurements were made within a warm shoe interior. Cold sensor calibration, however, would have resulted in an underestimation of pressure measurements inside the shoe. Errors due to limitations in calibration of the FSCAN system may be minimized by utilizing a repeated measures research design where the same sensor is used for all treatment trials on a given subject, and absolute pressure measurements are less important.

FSCAN peak pressure barefoot measurements exceeded $700 \mathrm{KPa}$ on 8 patients and $1380 \mathrm{KPa}$ on 3 patients. Cavanagh and Ulbrecht ${ }^{17}$ determined, using a piezoelectric pressure mat, that a $750 \mathrm{KPa}$ pressure was the threshold for injury in the neuropathic foot. The finding of high peak pressures in this leprosy population is consistent with previous studies on diabetic patients, which have found high foot pressures associated with neuropathy and plantar ulceration. ${ }^{3,4,18}$ Studies have not determined a risk level for high pressure in the neuropathic foot using the EMED and FSCAN systems.

\section{Conclusions}

Within the limitations of this study it is possible to conclude the following:

The sample footwear used by leprosy programmes for prevention of foot ulcers were effective in reducing plantar pressure.

2 There was a significant inverse relationship between pressure and insole thickness $\left(p<0 \cdot 001, R^{2}=0 \cdot 17\right)$.

3 The relative accuracy of the FSCAN inshoe pressure system was shown to be good within the limited testing conditions.

\section{References}

1 Hall DC, Brand PW. The etiology of the neuropathic ulcer. J Am Podiatry Assoc, 1979; 69: 173-7.

${ }^{2}$ Brand PW. The insensitive foot (including leprosy). In: Disorders of the Foot Jahss M (ed). Philadelphia: W. B. Saunders, 1982; 1266-86.

${ }^{3}$ Ctercteko GC, Dhanendran M, Hutton WC, Le Quesne LP. Vertical forces acting on the feet of diabetic patients with neuropathic ulceration. Br J Surg, 1981; 68: 608-14.

4 Veves A, Fernando DJS, Walewiski P, Bouton AJM. A study of plantar pressures in a diabetic clinic population. The Foot, 1991; 35: 89-91.

5 Fernando DJS, Masson EA, Veves A, Boulton AJM. Relationship of limited joint mobility to abnormal foot pressures and diabetic foot ulceration. Diabetes Care, 1991; 14: 8-11.

${ }^{6}$ Fritschi EP. Surgical Reconstruction and Rehabilitation in Leprosy. The Directory for Southern Asia Leprosy Mission, New Delhi, 1986; 227-44.

7 Ross WF. Footwear and the prevention of plantar ulcers. Lepr Rev, 1962; 33: 202.

8 Ward D. Footwear in leprosy. Lepr Rev, 1962; 33: 94-105.

9 Enna CD, Brand PW, Reed JK, Welch D. Orthotic care of the denervated foot in Hansen's disease. Orthot Prosthet, 1976; 30: 33-00.

10 Hampton GS. Therapeutic footwear for the insensitive foot. Phys Ther, 1979; 59: 23.

11 Shipley DE, Miner KM. The role of physical therapy in foot problems. In: Surgical Rehabilitation in Leprosy, McDowell F, Enna CD (eds). Baltimore: Williams \& Wilkins Co, 1974; 301-12.

12 Shipley DE. Clinical evaluation and care of the insensitive foot. Phys Ther, 1979; 59: 13.

13 Bauman JH, Girling J, Brand PW. Plantar pressures and trophic ulceration. J Bone Joint Surg, 1963; 45B: $652-73$. 
14 Cavanagh PR, Hewitt FG, Perry JE. In-shoe plantar pressure measurement: A review. The Foot, 1992; 2: 185-94.

15 Rose NE, Feiwell LA, Cracchiolo A. A method for measuring foot pressures using a high resolution, computerized insole sensor: the effect of heel wedges on plantar pressure distribution and center of force. Foot \& Ankle, 1992; 13: 263-70.

16 Birke JA, Sims DS. The insensitive foot. In: Physical Therapy of the Foot and Ankle, Hunt GC (ed). New York: Churchill Livingstone. 1988; 133-68.

17 Cavanagh PR, Ulbrecht JS. Plantar pressure in the diabetic foot. In: The Foot in Diabetes, Sammarco GJ (ed). Philadelphia: Lea \& Febiger. 1991; 54-70.

18 Boulton AJM, Hardisty CA, Betts RP, Franks CI, Worth RC, Ward JD, Duckworth T. Dynamic foot pressure and other studies as diagnostic and management aids in diabetic neuropathy. Diabetes Care, 1983; 6: $26-33$. 